\title{
Socio-Economic Potential of the Region and Its Evaluation
}

\author{
Valeria Anatolevna Cheymetova ${ }^{1} \&$ Elena Victorovna Nazmutdinova ${ }^{1}$ \\ ${ }^{1}$ Tyumen State Oil and Gas University, Tyumen, Russia \\ Correspondence: Elena Victorovna Nazmutdinova, Tyumen State Oil and Gas University, Volodarskogo Str., 38, \\ 625000, Tyumen, Russia.
}

$\begin{array}{lc}\text { Received: October 25, } 2014 & \text { Accepted: December 13, } 2014 \quad \text { Online Published: March 16, } 2015 \\ \text { doi:10.5539/ass.v11n7p74 } & \text { URL: http://dx.doi.org/10.5539/ass.v11n7p74 }\end{array}$

\begin{abstract}
At the moment the problem of determining the internal reserves of socio-economic development of the region becomes more important, the solution of which requires the development of new approaches to the definition of the essence, structure, methods for assessing the socio-economic potential.

Modern socio-economic situation and the need for constant adjustment of the processes occurring in the region require the development and formation of the conceptual and methodological tools of complex analysis of the level of development potential of the area. Now there are several basic approaches: integral evaluation of measures of socio-economic prosperity of the regions; integrated comprehensive performance evaluation based on the additive and multiplicative criterion.

One of the policy objectives of socio-economic development is the establishment of long-term regional development priorities. Comprehensive assessment of the dynamics of development of the Russian Federation suggests some stabilization of the socio-economic situation in them. However, some regions are significantly behind in terms of its socio-economic development. Therefore strategically important for Russia is a coherent state regional policy.

The aim of this study is the development of theoretical approaches, methodological principles, as well as the development of practical recommendations for a comprehensive assessment of the socio-economic potential of the region.

During the study of the theoretical framework for assessing the socio-economic potential of the technique in the balance of social and economic trends on the basis of the calculation of integral indices reflecting the substantial characteristics of the local units were constructed indicators (normalized values) underlying the integral evaluation of the balanced socio-economic potential of the region. The application of this approach allows to select the subjects of the Russian Federation, whose rating is the same when using the resource and effective approaches that demonstrates the effectiveness of management of socio-economic potential of territorial entities.
\end{abstract}

Keywords: potential, region, territory, socio-economic potential, structuring, classification, performance, integrated assessment, coefficient, monitoring

\section{Introduction}

Currently, an important issue to be resolved is the self-sufficiency of the socio-economic potential of the region. In this regard, the policy of the state and regional regulation should be focused on ensuring its consistent development. and the concept of management of the potential of the region should be focused on the identification, evaluation, determine the effectiveness of the use and increase due to acceleration processes, removing restrictions and increasing growth opportunities.

Socio-economic development of the area is based on an effective regional policy, which requires a different kind of resources composed in total the potential of the region.

Over the past two decades, there were radical changes in economic development at both the macro and meso-level, the effects of which become apparent only now. One of the policy objectives of socio-economic development of the region is the establishment of long-term regional priorities of its development. In this case, the most important task of regional policy is to create a system for monitoring the socio-economic development of the area, which will provide regional management bodies' complete, timely and reliable information on the processes occurring in the economic entity. The solution of this problem involves the development of an 
appropriate theoretical framework, the methodology for assessing the socio-economic potential of the region based on its structuring (Dynevan, 1969).

The term "potential" has been introduced in the scientific revolution 20-25 years ago, in the most general sense, it means "hidden features, power, strength." A broad interpretation of the concept of "potential" is in its consideration as "a source of opportunities, resources, stock, which can be activated, used to solve a problem or achieve a certain goal; capabilities of the individual, society and state in a particular field "(Cheymetova, 2014).

Combined expression of the material base of the region should be considered economic potential, which only take into account not only the volume located within a given territorial unit property, expressed in various quantitative indicators, but also the qualitative characteristics that determine the potential of the region. Therefore, in our opinion, for the study of the aggregate potential of the territory must be considered, first of all, the socio-economic, as the research of any kind components of only the economic potential of the region will inevitably lead to the inclusion of the social dimension, which characterizes the relationship between the people on the creation, development and effective use of resources in the region. In this context, the socio-economic potential of the area can be defined as "the capacity of the region at the use of the whole complex of its resources, using the characteristics of the existing and future structure of the economy, geographical location in order to improve the quality of life of the population" (Baksha et al., 2001).

Also it should be noted that now there is no single point of view on the structuring of the region's potential. Most often, researchers in the framework of the economic potential of the area mark out economic, industrial, investment, natural resources, financial, tax, financial, property, entrepreneurship, socio-demographic, population, production, etc. Some of them are the most extensive and include a number of the above.

Questions of the assess of the socio-economic potential of regions become increasingly important in today's economic environment. Development of theoretical and methodological framework for the assessment enhances the effectiveness of the control regions, the development and implementation of strategic plans and policy initiatives.

\section{Method}

Theoretical and methodological basis of the study are fundamental scientific works and applied development of domestic and foreign scholars in the field of economics and management of regional processes, as well as federal and regional regulations on the studied problems. Instrumental and methodological apparatus of the investigation is based on the methods of systematic and comparative analysis of the unity of the methods of abstraction, induction and deduction. The study also applied the methods of situational and logical framework analysis, expert assessments, the principal component analysis, statistical treatment and synthesis of information, methods of economic-mathematical modeling.

In this study, the following theoretical and methodological problems are required to solve, namely:

- Definition of the essential characteristics of the socio-economic potential and its structural components as economic categories and objects of statistical analysis;

- Development of integrated evaluation index of all structural components of the socio-economic potential and its method of calculation for the purpose of characterizing of volume and composition of resources, quality, balance, and other parameters that determine the potential;

- Development of methodological framework for the assessment of various elements of the potential;

An important aspect of research and solve of practical problems in the field of evaluation of territorial socio-economic potential is to determine its rational structure with an appropriate set of indicators. The generalization of the existing theoretical approaches to the structuring of the socio-economic potential of the region can be reduced to the four basic.

The first approach to the structuring of the socio-economic potential of differentiation is accompanied by the directions of efforts, resources and costs in its growth in the consumption of already accumulated. Some of the components are directly related to the accumulated reserves of resources (natural and environmental, socio-demographic, financial and property potential), some - to the possibilities of using the (intellectual and volitional, technical and technological, entrepreneurial potential of the market infrastructure, micro-economic potential), some - to the management system (kinetic, potential for integration). Mentioned structuring allows to determine the amount of resources which has the grounds and the possibility of their use. At the same time, consideration of such important condition as economic regional development is not present in the structuring. 
The second approach is mainly aimed at defining the investment attractiveness of the region and the assessment of investment risk. Therefore, authors of this method give the total name of the potential of the region as an investment, but its main components (labor, financial, natural resources, manufacturing, etc.) make it possible to talk about the social and economic potential of the area.

This structuring is different by simplified approach, but it contains all of the most important elements on which to judge the socio-economic development of the region. This technique requires some refinement for the most detailed study of local potentials.

A third approach to structuring is based on the fact that the socio-economic potential of the region is clearly divided into two major sections: economic, including six, and social including three private potentials. In this approach, the positive is that the economic bloc is adequately represented, but the social component does not contain the necessary to assess local potentials (social infrastructure, intellectual and volitional), which does not allow to judge the possibilities of socio-economic development of the region.

The presented to the consideration of socio-economic potential of the region three approaches have common elements (labor, natural resources, population, production, infrastructure, financial), and significant differences over its structuring (technical and technological, kinetic, microeconomic, consolidated, intellectually -volitional, consumption, innovation, etc.).

The fourth approach is based upon its division in three blocks that characterize the resource potential for economic development, as well as the willingness of the process:

- Basic unit of resource potentials;

- Potentials, ensuring economic development of the region;

- $\quad$ Block of potential readiness of the region to economic reform (Baksha et al., 2001).

In our view, this approach reflects the best the possibility for a comprehensive assessment of the socio-economic potential of the area, as it highlights all the necessary conditions: the availability of resources, their use and also reflected the willingness of the region to economic reform and development. Therefore, the fourth approach is taken as the basis for determining the structure of the socio-economic potential of the area, but with some adjustment, which is as follows.

As part of the first block of the local potential remains the same (natural resources, economic and geographic and demographic), as they fully reflect the resource base of the region - the availability of natural resources, their reserves, the climatic zone of the territory; reproduction and population of the region; the existence of transport infrastructure and the density of economic activity.

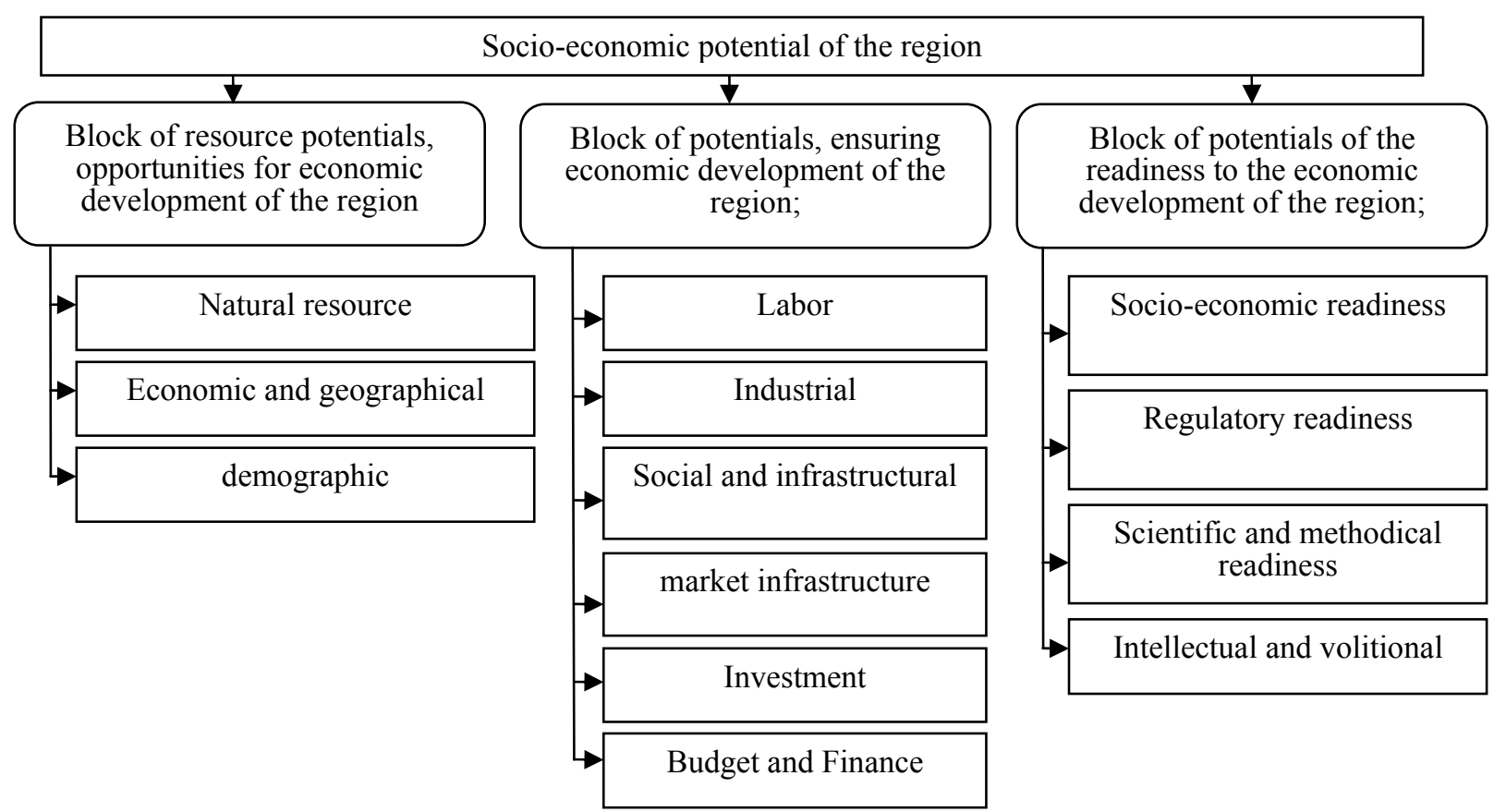

Figure 1. Structurizing of socio-economic potential of the region 
The second block is the labor potential, which reflects the region's enterprises providing human resources and their effective use; production potential - is, first of all, the existence and development of the power industry, production of their products; social and infrastructural potential determines the conditions and quality of life of the population, i.e. the development of vital infrastructure. Budgetary potential, showing the change only the revenue and expenditure of the regional budget, is supplemented by financial content (fiscal and financial capacity). Of the third unit investment potential is moved, showing the presence and investment in the region, which is a basic condition for economic development of the territory. It is also advisable to add the potential of a market infrastructure that characterizes the formation and development of entrepreneurship in the region. All changes further characterize the region's economic development.

The last block has remained virtually unchanged (the potential socio-economic readiness, regulatory preparedness, scientific and methodological status). But carrying out the processes for the development of the territory is not possible without the willingness of the population of this region, so this unit is turned on intellectual and volitional capacity, reflecting the level of professional development of the population, its ability for sustainable choice of objectives and activities to implement them (see Figure 1).

Proposed structuring of the socio-economic potential is based for a comprehensive evaluation of the effectiveness of its use and development, which is essential in the generation options and the rational of strategic choice of territorial development, the formation of economically justified both state and regional policy.

This structuring is different by simplified approach to its forming, but it contains from all of the most important elements on which to judge the socio-economic development of the region. This technique requires the structuring of some refinement for the most complete characterization of the components of the socio-economic potential of the region, their analysis, forecasting and in building long-term plans (Daly, 1992).

There are many interpretations of the nature and purpose of assessment of the socio-economic potential of the region.

In this regard, there is a need to identify, quantify and analyze the socio-economic potential of a specific system. The complexity of the internal structure, the variety of elements that forms the social and economic potential of the region, determines the need for a comprehensive approach to assessing the effectiveness of its functioning. The applied methods are generally limited to qualitative or quantitative characteristics of individual elements of the socio-economic potential (Mamasieva, 2011; Magomedov \& Mamasieva, 2012; Dubrovin, 2006).

After analyzing the variety of approaches used to assess the socio-economic status of the territories, we came to the conclusion that no one of the currently available methods can not be considered universal, since they include a large set of indicators, which are difficult to analyze the current socio-economic situation. In addition, many studies are not comprehensive and may not fully reflect the true state of the regions. In the scientific literature, there are four main approaches to the assessment of the socio-economic potential - industrial, resource, score, rating.

Modern socio-economic situation and the need for constant adjustment of the processes occurring in the region require the development and formation of the tools of complex analysis of the level of development of its potential. Now there are several basic approaches: integral evaluation of measures of socio-economic prosperity of the regions; integrated comprehensive evaluation based on the additive and multiplicative criterion (Gahill \& Sanchez, 2001; Ratvortseva, 2008).

\section{Methodological framework for the calculation of the integral index of socio-economic development}

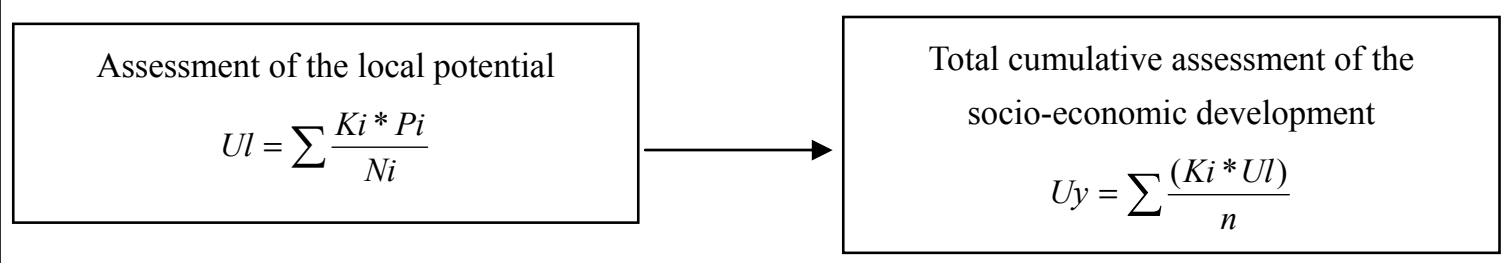

Indicator rating:

less than 1 - the situation is unfavorable;

1 - the situation is equivalent to the mean

Figure 2. Algorithm for integrated assessment of the level of socio-economic potential of the area 
Legend:

$\mathrm{Ki}$ - the coefficient of the significance of i-th particular indicator (the sum of the coefficients is equal to 1 for a group of local potentials);

$\mathrm{Pi}$ - the actual value of the $\mathrm{i}$-th particular indicator;

$\mathrm{Ni}$ - the standard value of $\mathrm{i}$-th particular indicator;

$\mathrm{n}$ - the total number of potential private

In our opinion, the evaluation and the balanced socio-economic trends should be based on the calculation of integral indices. On the basis of the ordered by the author system of indicators reflecting substantial characteristics of the local units were constructed indicators (normalized values) underlying the integral evaluation of the balanced socio-economic potential. We tend to approach the developed by O.M. Prokapalo, but with the adjustment, which is to include indicators that reflect the economic substance of the changes taking place in the region (Prokapalo 2010). Approbation calculations carried out by the proposed method, revealed disparities of territorial development and the need for a policy of "leveling" in the social and labor sphere (see Figure 2).

In the proposed method to assess the level of development and use of socio-economic potential is carried out on indicators that reflect the development of each of the local potentials. Indicator - is a key economic indicator, which reflects the trend of economic development. The author proposes an adjustment of their structure on the basis of the proposed structuring of the socio-economic potential of the area (to bring up to three indicators), unidirectional (only reflect a positive trend), the possibility of their valuation) (Cheymetova, 2003).

The normalization procedure is set on a formula. Value of normalized parameters should tend to one.

$$
K h i=K f i / K \max i
$$

where Kmaxi - the maximum value of the $i$-th index in the set of indicators;

$\mathrm{Kfi}$ - the actual value to be rationing of the i-th index.

The application of this approach allows to select the regions, whose rating is the same when using the resource and effective approaches that demonstrates the effectiveness of management of resource potential for the last years. The results of calculation of the integral elements of indicators to measure the socio - economic potential of the region makes it possible to determine the contribution of individual regions of the development of the entire economy of the country as a whole.

\section{Results}

In accordance with this aim, the study produced the following results:

- Theoretical study and analysis of the provisions defining the concept and structure of the socio-economic potential, identification of its role in ensuring the balanced socio-economic processes in the region;

- Specification of the methodological framework for assessing the socio-economic potential to justify the regulation of economic development is produced. The practical interest of this method lies in the fact that, in conjunction with the determination of the level of socio-economic development of the region will be possible to determine the effectiveness of management of the region and this will give an opportunity to reduce regional disparities in terms of socio-economic status and quality of life of the population.

Theoretical and practical significance of the study lies in the fact that they can be used in the practice of regional management bodies of executive power in the assessment and management of restructuring industries, complexes, industrial plants. Contained in the study analytical generalizations and methodological developments can be used to develop strategies and programs for socio-economic development of the region, predicting the development of the basic reproductive processes.

\section{Discussions}

Potential of the region - is not only made by the region an economic and social level, but also those reserves, which are available on a given territory. With a view to identifying existing reserves it is necessary to study the socio-economic potential, capacity of which is not an end of the regional economy, as a means to ensure the effective functioning of the reproductive process in general.

In terms of overall economic potential represents a set of available resources, opportunities in a particular area. Such an understanding of the potential can be applied to various areas of social life, depending on whether any 
of the features and tools in question. Socio-economic potential of the territory (region) - is "the set of all available resources within its borders, as involved in the process of social production and social development, as well as those that can be used in the future for economic growth and improve the quality of life of the population of the territory" (Lukin, 1988).

Socio-economic potential as an economic category reflects the complex, multidimensional, aggregated and consolidated processes, communication and relationships. Because of this diversity and complexity of the category of socio-economic potential of the investigated enough, it is not seen as an object and subject of an independent, focused and systematic study of both the socio-economic potential of the state, and with respect to the potential of the Russian Federation (Korolev \& Figurnov, 1985).

The basis of the concept of "social and economic potential" is the term "potential", which carries a double meaning: on the one hand, it characterizes, according Ozhegova S. I., Shvedova N. Y., the "degree of power in some respect" and on the other - indicates that this power is hidden, because it is not only "the totality of what something means," but also "opportunities" (Ozhegov \& Shvedova, 2003).

In a large dictionary term economic potential reflects a brief understanding of the "hidden features, power, strength." (Great Dictionary of Economics, 2000). A broad interpretation of the semantic concept of "potential" is in its consideration as "a source of opportunities, resources, reserves, which can be brought into action, used to solve a problem or achieve a certain goal; capabilities of the individual, society and state in a particular field "(Svobodin, 1991).

Baksha N. V., Gamukin V. V., and Svintsova A. P. consider the concept of potential with two positions: "a system of material and labor factors (conditions), ensuring the achievement of the purposes of production," as well as "an opportunity through the use of resources to solve complex tasks entrusted to it" (Baksha et al., 2001). Last interpretation, is the most complete, since it considers the potential as an opportunity to achieve the objectives.

Feature to determine the potential of the resource position, which is the most interesting from the point of view of the research potential of the territory lies in the interpretation of the capacity as a set of resources that can produce a certain amount of wealth. For example, E. B. Figurnov considers that the potential "describes the resources of production, quality and quantity of the parameters determining the maximum capacity to produce wealth at any given moment" (Queens and figured, 1985). a similar position V. I. Svobodin has who considers potential as "a set of co-operating resources with the ability to produce a certain amount of production" (Svobodin, 1991). According to D. K. Shevchenko, the potential is a "combination of industrial resources connected to the production process, with certain potential abilities in the production of goods and services" (Shevchenko, 1984). Some authors define the concept of "potential" from the perspective of the resource approach. I. I. Lukinov considers the economic potential as the "quantity and quality of resources available to one or another economic system "' (Lukin, 1988). Followers of the resource approach are considered "potential" as a static value, excluding the ability of the economic system to the efficient use of available resources. D. A. Chernikov reflected this aspect in his definition of economic potential, "a collection of resources without real relationships that are emerging in the process of production" (Chernikov, 1981).

If we consider the "potential of the area," it is possible to identify a number of approaches most accurately reflect its definition. For example, the combined expression of the material base of the region considers the economic potential, which takes into account not only the volume located within a given territorial unit of the property, expressed in various quantitative indicators, but also the qualitative characteristics that determine the potential of the region (Baksha et al., 2001).

To the accurately determination the nature of potential territorial entity should use the concept not economic, and socio-economic potential. Study its components inevitably leads to the inclusion in the consideration of the social dimension, determined by the ratio between the people in the process of creation, development and the use of the region's potential.

Socio-economic potential of the area - a "potential of the region with the use of the whole complex of its resources, the use of the features of the existing and future structure of the economy, geographical location to act in order to improve the quality of life "' (Baksha et al., 2001).

For a more precise definition of the socio-economic potential of the area it is necessary to make a distinction on those components of which it is composed. At the moment, there are many approaches to the structuring of the socio-economic potential, so it is advisable to consider the key of them (Enright, 2000). 
For example, the combined expression of the material base of the region considers the economic potential, which takes into account not only the volume located within a given territorial unit of the property, expressed in various quantitative indicators, but also the qualitative characteristics that determine the potential of the region.

In our opinion, to determine the exact nature of potential territorial entity should use the concept not economic, and socio-economic potential. Study its components inevitably leads to the inclusion in the consideration of the social dimension, determined by the ratio between the people in the process of creation, development and the use of the region's potential.

Socio-economic potential of the area is a "potential of the region with the use of the whole complex of its resources, the use of the features of the existing and future structure of the economy, geographical location to act in order to improve the quality of life".

\section{Conclusions}

Traditionally, the socio-economic potential is understand the "power", the ability of the socio-economic system to the production and reproduction of its structural elements. This approach was the result of a well-established paradigm of a limited and well-defined set of objectives of economic activity, which functioned on the basis of a planned economy.

However, in conditions of freedom of economic entities becomes apparent that the problem is not only the lack of funds for a particular purpose, but also the formation and selection of goals themselves. Potential capabilities of the system are open only through the competition ("Competition as an opening procedure"), which acts as a catalyst for the discovery of new ways to link the factors of production, the creation of new technologies, new products and new markets. Therefore, one of the key factors determining the prospects of socio-economic system is the degree of competitiveness of the economic agents.

In the study, an approach to the consideration of socio-economic potential of the region is based as a set of resources of the area and the properties that define how sustainable and effective functioning of the socio-economic system under varying environmental conditions. The result of the development acts, first of all, the growth of the welfare of the population. In this aspect, we can also consider the extent and effectiveness of the use of socio-economic potential of the region.

Socio-economic potential as an economic category reflects the complex, multidimensional, aggregated and consolidated processes, communication and relationships. Because of this diversity and complexity of the category of socio-economic potential is not investigated enough, it is not seen as an object and subject of an independent, focused and systematic study of both the socio-economic potential of the state, and with the respect to the potential of the Russian Federation.

The paper presents the urgency of identifying and assessing the socio-economic potential of the region. A theoretical study of approaches to the structuring of the socio-economic potential of the area is made, on the basis of which own methodological tools is offered that allow in further studies to make a comprehensive assessment of the individual subjects of the Russian Federation. In the proposed approach the key conditions are highlighted that determine the readiness of the region to economic reform and development, which is essential in the generation options and the rationale of strategic choice of territorial development, as well as in the formation of an economically viable state and regional policy.

In the study different approaches are systemized to the structuring of the socio-economic potential of the region. Additions made to the methodology of integrated assessment of socio-economic potential of the region, based on the method of integral estimates, which allows to determine the overall availability of resources, as well as the security of their individual views.

\section{References}

Antonioli, D., \& Mazzanti, M. (2009). Techno-organisational strategies, environmental innovations and economic performances. Micro-evidence from an SME-based industrial district. J. of Innovation Economics. De Boeck Université, 3, 145-168.

Baksha, N. V., Gamukin V. V., \& Svintsova, A. P. (2001). Aspects of the budget: the imperative, economic, financial, tax, consumables and social. Moscow: IPO Profizdat.

Becker, G. S. (2007). Social economics: market behavior in a social environment. London: Belknap press of Harvard univ. press.

Blyakhman, A. A. (2008). Testing the comparative method of the assesment the economic status of the regional branches of industry. Regional economics and management: electronic scientific journal, 14, 33-38. 
Borisov, A. B. (2011). Big Dictionary of Economics. M.: World of Books.

Chernikov, D. A. (2009). Efficiency of utilization of productive capacity and final economic results. Economics, 10.

Cheymetova, V. A. (2003). Socio-economic potential of the region: assessment and balanced development. Tyumen: Oil and Gas University.

Cheymetova, V. A. (2014). Theoretical and methodological approaches to determining the socio-economic potential of the area. Economics and Business, 1(3), 236-238.

Dubrovina, N. A. (2006). Evaluating the effectiveness of regional governance. Vestnik of SSU, 8.

Enright, M. J. (2000). Survey on the Characterization of Regional Clusters: Initial Results. Working Paper, Institute of Economic Policy and Biasness Strategy: Competitions Program? University of Hong Kong.

Florida, R. (2008). Who's Your City: How the Creative Economy is Making Where to Live The Most Important Decision of Your Life. N-Y.: Basic Books.

Korolev, M. A., \& Figure, E. B. (2010). Statistics and economic analysis in the management of the economy. M.: Economy.

Lukin, I. I. (2013). Approach to determination of significant hierarchical levels of the company in the analysis of prospects of its development. T-Comm, 1 .

Magomedova, M. M., \& Mamasieva, D. A. (2012). Estimation and forecasting of socio-economic potential of the region. Makhachkala Ltd. Publishing House "Science Plus".

Mamasieva, D. A. (2011). Methodological aspects of assessing the socio-economic potential of the region. Regional problems of economic transformation, 4, 33-37.

Ojegov, S. I., \& Shvedova, N. Y. (2010). Dictionary of Russian: 80000 words and phraseological expressions (4th ed.). Russian Academy of Sciences. Russian Language Institute.

Prokapalo, O. M. (2010). Spatial differentiation of macroeconomic indicators in the Russian economy. Spatial Economics, 1, 36-54.

Rastvortseva, S. N. (2008). The essence of the socio-economic benefits of development in the region. Regionology, 4, 22.

Shevchenko, D. C. (2009). Problems and prospects of increase of efficiency of innovative capacity of the enterprise. Vladivostok: Izd Dalnevost. Univ.

Svobodin, V. A. (2011). Complex economic analysis of economic activity. M: Dashkov.

\section{Copyrights}

Copyright for this article is retained by the author(s), with first publication rights granted to the journal.

This is an open-access article distributed under the terms and conditions of the Creative Commons Attribution license (http://creativecommons.org/licenses/by/3.0/) 